\title{
Delta Wave by ECG Finding
}

National Cancer Institute

\section{Source}

National Cancer Institute. Delta Wave by ECG Finding. NCI Thesaurus. Code C62258.

An electrocardiographic finding of initial slurring (delta wave) of the QRS complex due to the presence of an accessory pathway. This characteristic ECG pattern is typically seen in Wolff-Parkinson-White syndrome. (CDISC) 